\title{
The First Massive Open Online Course of the European Psychiatric Association on Cognitive and Behavioral Therapy
}

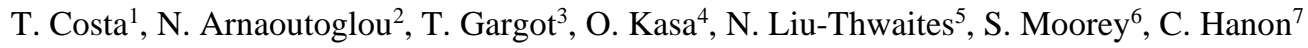 \\ ${ }^{1}$ Newcastle University and Cumbria, Northumberland, Tyne and Wear NHS Foundation Trust Newcastle upon Tyne, United \\ Kingdom \\ ${ }^{2}$ Cambridgeshire \& Peterborough NHS Foundation Trust and Department of Psychiatry, University of Cambridge, Cambridge, \\ United Kingdom; Memory \& Cognitive Functions Clinic, 1st Department of Psychiatry, "Papageorgiou" Hospital, Aristotle \\ University of Thessaloniki, EFPT Psychotherapy Working Group and EPA Psychotherapy Section, Thessaloniki, Greece \\ ${ }^{3}$ CHART Laboratory - EA 4004, TIM, Paris 8 University, 93526, Saint Denis, France Child and et de 1'Adolescent Psychiatry, \\ Pitié Salpêtriére - Charles Foix, Hospitals of Paris, 75013, Paris, France; ISIR, Sorbonne Université, EFPT Psychotherapy \\ Working Group and EPA Psychotherapy Section, 75005, Paris, France \\ ${ }^{4}$ Riga East University Hospital, EFPT Psychotherapy Working Group and EPA Psychotherapy Section, Riga, Latvia \\ ${ }^{5}$ South London and Maudsley NHS Trust, London, United Kingdom \\ ${ }^{6}$ South London and Maudsley NHS Trust, London, United Kingdom; King's College, London, United Kingdom \\ ${ }^{7}$ Regional Center Ressources in Psychiatry for Old People, DMU Psychiatry and Addictology, Hospitals of Paris - University \\ of Paris, EPA Committee of Education, Paris, France
}

Corresponding Author Email: Tiago.da-Silva-Costa@newcastle.ac.uk; nikitas.arnaoutoglou@gmail.com; thomas_gargot@hotmail.com; dr.olga.kasa@gmail.com; natasha.liuthwaites@gmail.com; s.moorey@btopenworld.com; cecile.hanon@aphp.fr

https://doi.org/10.18280/mmc c.811-403

Received: 7 August 2020

Accepted: 26 October 2020

\section{Keywords:}

psychotherapy, CBT, MOOC, online, training

\begin{abstract}
Introduction: Psychiatric trainees lack psychotherapy training. In 2018, the European Psychiatric Association (EPA) offered a Massive Open Online Course (MOOC), "Introduction to Cognitive Behavioural Therapy". We will present an overview of the course participants and engagement metrics, and propose improvements for future courses. Methods: Non-identifiable participant information was collected through a welcome survey. Additional data were internally extracted, including demographic information, interests, educational background, learning objectives, completion and satisfaction rate. Engagement strategy questionnaires were distributed and screen time calculated. Results: There were 7.116 enrollments, 1.504 completed the welcome survey and $954(13 \%)$ the overall course. The three most represented countries were: Greece (18\%), France (8\%) and the UK (7\%). Psychologists and psychology students represented $41 \%$ of the initial participants, psychiatrists and psychiatry trainees $33 \%$. Conclusion: The MOOC achieved its primary goals and received a wide acceptance. The dropout rate was lower than similar online courses. Improvements and amendments are suggested.
\end{abstract}

\section{INTRODUCTION}

Communication and psychotherapy skills are core psychiatry competencies [1]. Depression is the most disabling disorder in the world according to the World Health Organization [2]. The total annual cost of depression in Europe has been estimated at $€ 118$ billion in 2004 [3]. This makes it the brain disorder with the highest economic burden in Europe, accounting for $33 \%$ of the total cost, corresponding to $1 \%$ of Europe's economy (by GDP) [3]. Its first line treatments are psychotherapy and antidepressants, such as selective serotonin reuptake inhibitors. However, in a survey of 869 French psychiatry trainees, psychotherapy training was identified as being hardly implemented [4]. The European Federation of Psychiatric Trainees (EFPT), collecting answers from 574 trainees living in 22 different European countries, found strong motivation for training in psychotherapy $(>90 \%)$, but scarcity of available resources [5]. Psychotherapy training has been identified as the most relevant issue for psychiatric trainees, even before salary and working conditions [6]. Online focus groups with European psychiatric trainees and young psychiatrists, showed that e-learning courses are valued as lifelong learning opportunities [7] and could be helpful to address this issue.

Cognitive Behavioural Therapy (CBT) is a well-known and widely used manualized psychotherapy, being first-line treatment in many countries for mood disorders and other pathologies [8]. Given its widespread use and relevance, training in $\mathrm{CBT}$ is in great demand, including online courses [9]. Online CBT training has some advantages when compared to face-to-face, including lower overall costs and accessibility for participants at any time and from any part of the world.

Massive Open Online Courses (MOOCs) have been a popular learning method since 2012 [10]. They are open access online courses, available to a worldwide audience, potentially with unlimited participation. They can make use of 
traditional teaching methods - reading materials, videos of lectures and questionnaires - and also interactive components, such as discussion forums. These should foster engagement and promote interactions between participants and facilitators, with reflective questions to provoke and support metacognitive processes, helping the participants to learn, and with implementing processes into their practice [11]. Still, there isn't any face-to-face experience, and significant dropout rates are common. Also, the absence of surveillance during assessments increases the risk of fraud.

In April and May 2018, the EPA ran the "Introduction to CBT" MOOC. It consisted of an introductory module and 4 different chapters, each composed of 4 to 8 lessons. The syllabus focused on the past and present of CBT, CBT for anxiety and depression, CBT for the treatment of depression (based on a clinical case), and the overall value of CBT techniques for psychiatric practice. Each chapter was made available sequentially on a weekly basis, taking 2 to 3 hours to complete. Participants were also encouraged to engage in structured discussion forums, moderated by facilitators. Participants were free to complete the course at their own pace, but the certificate of completion was only unlocked when all of the syllabus was completed. There was no summative evaluation. In a recent viewpoint, we presented the challenges of teaching CBT with a MOOC [12].

Here, we will present an overview of the course participants in the EPA MOOC on CBT, respective engagement metrics, and also propose improvements for future courses.

\section{METHODS}

With each participant's informed consent, anonymized individual data were gathered through a structured welcome survey, cross-sectionally. Completion of this questionnaire was voluntary and did not affect course participation. Questions included demographics, educational background, motivation for participation, occupation and years of experience.

We also used anonymized longitudinal data from the activity on the Canvas platform. This included learning aims and outcomes, interests, completion and satisfaction rate. We separately calculated screen time and page views for each chapter and video session. Lastly, participants also responded to engagement strategy questions.

We followed the STROBE guidelines for reporting observational studies [13].

\section{RESULTS}

A total of 7.116 participants enrolled and the welcome survey captured 1.504 answers. Only $26 \%$ of the participants finished the first week of the MOOC and validated the first formative quiz. The drop-out rate during the second and third weeks was, respectively, $8 \%$ and $2.5 \%$. Only $13 \%(n=954)$ of the total enrolled participants completed the course.

The 10 most represented countries in screen watch time $(61 \%$ of the total) were Greece (18\%), France $(8 \%)$, UK $(7 \%)$, Poland (6.4\%), Russia (4.6\%), Ukraine (4.1\%), Australia (3.6\%), Romania (3.6\%), Turkey (3.3\%) and Egypt (3.2\%). The remaining 39\% came from 39 other countries (Figure 1).

Females represented $76 \%$ of the participants and $45 \%$ were in their 20 s, with $31 \%$ being in their 30 s and $23 \%$ over 40 years old.

Psychologists and psychology trainees were the largest group $(41 \%)$, followed by psychiatrists and psychiatry trainees $(32 \%)$. Most of the board-certified psychiatrists were under 30 years old (34\%), having two years or less of experience. Other represented groups included different medical specialists, nurses, mental health practitioners, social workers, teachers, students from other areas, as well as patients and caregivers.

For most of the participants (84\%) this was their first MOOC, 63\% had never trained in CBT before, and 53\% didn't have previous experience in any other kind of psychotherapy. The main motivations for enrollment were career development (27\%) and educational purposes $(22 \%)$.

The topic played a 'very important' (80\%) and 'important' $(19 \%)$ role for participants (Table 1$)$. The perceived quality of the faculty had a pivotal role in registration (82\%). A certificate of completion was 'important' for $41 \%$ and 'very important' for $34 \%$. The course being free was 'very important' to $45 \%$ and 'important' to $44 \%$. The most popular device used to follow the MOOC was a personal computer (77\%), followed by smartphones $(16 \%)$ and tablets $(7 \%)$.

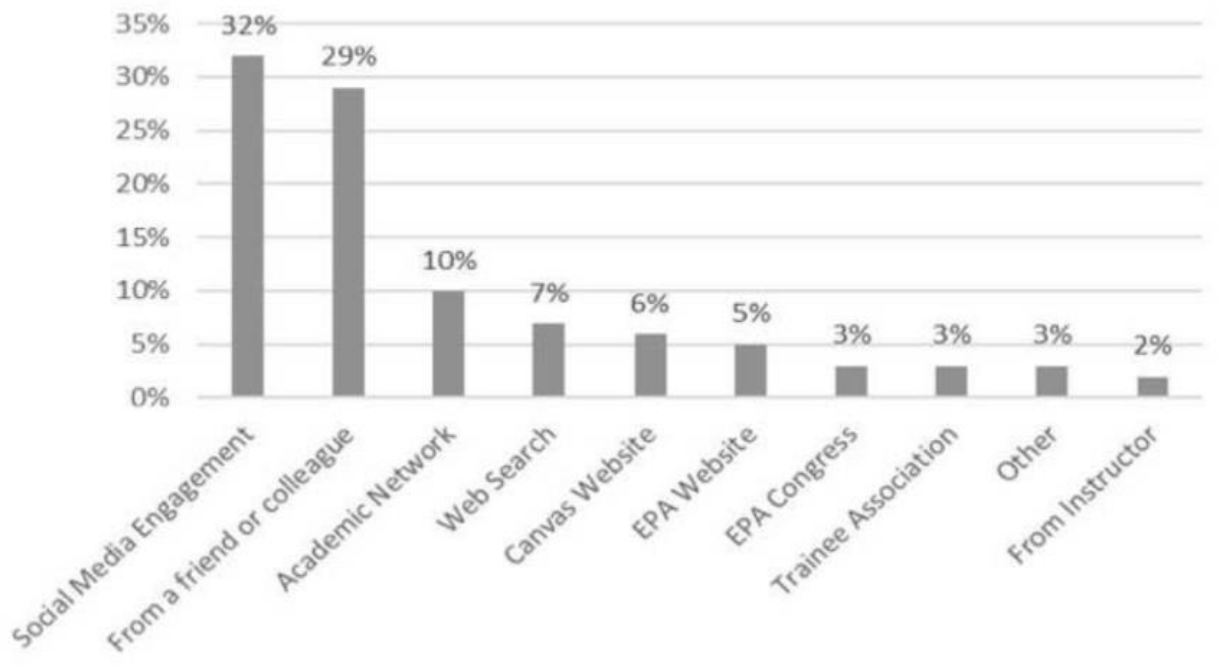

Figure 1. How participants learned about the MOOC 
Table 1. Participant's video watchtime, views and average view duration (by nationality)

\begin{tabular}{cccc}
\hline Country & $\begin{array}{c}\text { Video watch } \\
\text { time } \\
\text { Minutes }(\% \text { of } \\
\text { total) }\end{array}$ & $\begin{array}{c}\text { Views } \\
\text { N(\% of } \\
\text { total) }\end{array}$ & $\begin{array}{c}\text { Average view } \\
\text { duration } \\
\text { Minutes }\end{array}$ \\
\hline Greece & $44.878(18)$ & $6.448(16)$ & $6: 57$ \\
France & $20.193(8)$ & $3.567(9)$ & $5: 39$ \\
UK & $17.797(7)$ & $2.490(6.3)$ & $7: 08$ \\
Poland & $16.307(6.4)$ & $2.519(6.4)$ & $6: 28$ \\
Russia & $11.664(4.6)$ & $2.009(5.1)$ & $5: 48$ \\
Ukraine & $10.437(4.1)$ & $1.885(4.8)$ & $5: 32$ \\
Australia & $9.110(3.6)$ & $1.152(2.9)$ & $7: 54$ \\
Romania & $9.103(3.6)$ & $1.416(3.6)$ & $6: 25$ \\
Turkey & $8.414(3.3)$ & $1.338(3.4)$ & $6: 17$ \\
Egypt & $8.056(3.2)$ & $1.528(3.9)$ & $5: 16$ \\
\hline
\end{tabular}

\section{DISCUSSION}

Despite the high attrition rate, 954 participants completed all four modules of the first EPA MOOC on CBT. The retention rate was around twice that of the average MOOC [14]. This could be a reflection of the quality of the MOOC, as inferred from participant feedback, or the underlying need for training in psychotherapy $[4,5]$. Participation can be amplified by collaborating with patient associations like the Global Alliance of Mental Illness Advocacy Networks-Europe (GAMIAN) or the European Federation of Associations of Families of People with Mental Illness (EUFAMI). The latter endorsed the Caring for People with Psychosis and Schizophrenia MOOC developed by King's College London [15].

The MOOC format is perhaps particularly attractive for those who already have a basic training in psychiatry or psychology in a more classical academic context. Still, engagement could be improved using insights from the selfdetermination theory, which postulates 3 psychological needs: competence (sense of efficacy), autonomy (volition and personal agency) and related-ness (social interactions) [16].

The use of game mechanics could improve engagement in MOOCs [17]. Some of these principles were used for the 2 nd EPA online course on Motivational interviewing (achievement badges, improving the feeling of competence) but others could be used in future EPA MOOCs; including simple strategies to improve related-ness from social networks (such as "likes" for the best questions or comments), competitive activities between participants (e.g., best quiz grades, or a score-time of completion on the European Association of CBT serious game, that teaches the basic principles of CBT and introduces its famous researchers [18]), or a status bar of completion visible for other participants, making educational activities intrinsically more rewarding.

To assess competence, foster reflection and prepare implementation in clinical practice, other strategies could include: (1) patient simulation supported by avatar patients [19-21], (2) role plays with peers, to foster relatedness as well [22], (3) group supervision, particularly relevant for the development of autonomy which could allow learning by teaching principles [23], or (4) online journal clubs to learn to read scientific literature, such as those that EFPT has organized [24-27]. Video subtitles might be necessary to teach a global audience that includes non-native English speakers [7], also improving accessibility for deaf and hard-of-hearing people.
A trace-based approach could help to identify user's engagement by assessing competence, autonomy and relatedness, thanks to features collected following the trace theory approach [28] or unsupervised machine learning algorithms [29].

We did not include any summative assessments, and accreditation remains challenging for online courses. Peer assessments have been developed for other MOOCs [30, 31]. For psychotherapy training, we propose that a hybrid system, where both online and face-to-face components could be useful, akin to that of the Human Brain Project summer schools [32]. After participants completed the online content, they could have an advanced face-to-face course, including summative and practical skills evaluation, which would make it more valuable towards continuing professional development.

There are some limitations to this study. There could be a recruitment bias, with some countries being over-represented, which was perhaps linked to the origin of some of the MOOC coordinators (Greece, UK and France). Participants who replied to the surveys might be more motivated, and more positive overall towards the MOOC. Given the high burden of depression (and brain disorders in general), we think it is important that these courses be of a higher quality, and as engaging as possible. They should also be free of charge to reach a large audience. In the next EPA MOOCs, it would be worthwhile to measure not only the feasibility, audience and the theoretical knowledge, but also the practice of the participants, and whether, with direct supervision or peer group supervision, this could allow learning by teaching principles.

\section{ACKNOWLEDGMENT}

We would like to thank the EPA Committee of Education members, Lara Le Noan - EPA Project Manager for Education, Ethics, ECPC, Ms. Valérie Vergez - Pedagogical Consultant as well as Dr. Stirling Moorey and the invited speakers for their contribution in the course: Ms. Suzanne Byrne, Dr. Isaac Marks, Dr. Deborah Cullen, Dr. Alice Kerr, Ms. Sophie Mayes, Dr. Abigail Pain, Ms. Sarah Worral, Dr. Steven D. Hollon, Prof. David Kingdon, Dr. Herbert Steiner and Dr. Chris Williams.

NA was in Cambridge and now is working for the Memory \& Cognitive Disorders clinic, Papageorgiou General Hospital, Thessaloniki, Greece.

The EPA funded the course. Lara le Loan was funded by the EPA and was not involved in the writing and interpretation of the survey findings.

\section{REFERENCES}

[1] Brittlebank, A., Hermans, M., Bhugra, D., Pinto da Costa, M., Rojnic-Kuzman, M., Fiorillo, A., van der Gaag, R.J. (2016). Training in psychiatry throughout Europe. European Archives of Psychiatry and Clinical Neuroscience, 266(2): 155-164. https://doi.org/10.1007/s00406-016-0679-4

[2] World Health Organization (2019). Fact sheet on Depression. Retrieved March 16, 2020, from https://www.who.int/news-room/factsheets/detail/depression

[3] Sobocki, P., Jönsson, B., Angst, J., Rehnberg, C. (2006). 
Cost of depression in Europe. Journal of Mental Health Policy and Economics, 9(2): 87-98.

[4] Van Effenterre, A., Azoulay, M., Champion, F., Briffault, X. (2013). La formation aux psychothérapies des internes de psychiatrie en France: Résultats d'une enquête nationale. L'Encéphale, 39(3): 155-164. https://doi.org/10.1016/j.encep.2012.05.003

[5] Gargot, T., Dondé, C., Arnaoutoglou, N.A., Klotins, R., Marinova, P., Silva, R., Sönmez, E. (2017). How is psychotherapy training perceived by psychiatric trainees? A cross-sectional observational study in Europe. European Psychiatry, 45(Supplement C): 136-138. https://doi.org/10.1016/j.eurpsy.2017.05.030

[6] Matutyte, L. (2018). Psychotherapy within psychiatric training: Are we improving? Poster presented in EPA congress, Nice, France, 2018. Retrieved April 12, 2019 , from https://www.europsy.net/past-future-congresses/ website: $\quad$ https://i0.wp.com/efpt.eu/wpcontent/uploads/2018/02/EFPT_EPA-2018-3.jpg

[7] Casanova Dias, M., Giacco, D., Hanon, C. (2017). Early career psychiatrists' preferences on e-learning: Viewpoint from the EPA Committee on Education. European Psychiatry: The Journal of the Association of European Psychiatrists, 42: 86-88. https://doi.org/10.1016/j.eurpsy.2016.12.003

[8] David, D., Cristea, I., Hofmann, S.G. (2018). Why cognitive behavioral therapy is the current gold standard of psychotherapy. Frontiers in Psychiatry, 9: 4. https://doi.org/10.3389/fpsyt.2018.00004

[9] Beck Institute for Cognitive Behavior Therapy. [cited 2019 Apr 12]. Online Training [Internet]. Available from: https://beckinstitute.org/get-training/online-training

[10] Breslow, L., Pritchard, D.E., DeBoer, J., Stump, G.S., Ho, A.D., Seaton, D.T. (2013). Studying learning in the worldwide classroom research into edX's First MOOC. Research \& Practice in Assessment, 8: 13-25.

[11] Schon, D.A. (1984). The Reflective Practitioner: How Professionals Think in Action, 5126: Basic books.

[12] Gargot, T., Arnaoutoglou, N.A., Costa, T., Sidorova, O., Liu-Thwaites, N., Moorey, S., Hanon, C. (2020). Can we really teach cognitive behavioural therapy with a massive open online course? European Psychiatry, 63(1): e38. https://doi.org/10.1192/j.eurpsy.2020.29

[13] STROBE. (2008). STROBE Statement: Home. Retrieved April 16, 2019, from https://strobestatement.org/index.php?id=strobe-home

[14] Reich, J., Ruipérez-Valiente, J.A. (2019). The MOOC pivot. Science, 363(6423): 130-131. https://doi.org/10.1126/science.aav7958

[15] Onwumere, J. (2018). Caring for People with Psychosis and Schizophrenia - On. Retrieved April 12, 2019, from https://www.futurelearn.com/courses/caring-psychosisschizophrenia

[16] Ryan, R.M., Deci, E.L. (2000). Self-determination theory and the facilitation of intrinsic motivation, social development, and well-being. American Psychologist, 55(1): 68 .

[17] Gené, O.B., Núñez, M.M., Blanco, Á.F. (2014). Gamification in MOOC: Challenges, opportunities and proposals for advancing MOOC model. TEEM '14, 215220. https://doi.org/10.1145/2669711.2669902

[18] Alexander Örtenholm, Free Online windows video game presented during European Association of Behavioural and Cognitive Therapies Congress (2016). EABCT2016 - THE GAME. Retrieved April 12, 2019, from http://eabct2016.org/thegame/

[19] Combs, C.D., Sokolowski, J.A., Banks, C.M. (2015). The Digital Patient: Advancing Healthcare, Research, and Education. John Wiley \& Sons.

[20] Skip Rizzo. (2018). MIND Playthrough. Retrieved from https://www.youtube.com/watch?v=b1eEtU_zWh8\&fea ture $=$ youtu.be

[21] Trimmer, M. (2019). Motivational Interviewing Learning Environment and Simulation (MILES). Retrieved April 12, 2019, from http://ict.usc.edu/prototypes/miles/

[22] Projet EIFFELa: Le bilan. (2020). FUN-MOOC. Retrieved April 30, 2020, from //www.funmooc.fr/news/projet-eiffela-le-bilan/, published January, 16th 2020

[23] Stollhans, S. (2016). Learning by Teaching: Developing Transferable Skills. Employability for languages: A handbook, 161-164.

[24] De Freitas, D. (2018). EFPT Journal Club \#2: Biology and Future of Psychoanalysis. Retrieved April 15, 2019, from https:/www.facebook.com/events/320502932062976/

[25] Gargot, Thomas. (2017). EFPT Journal Club \#1: Tetris in PTSD prevention. Retrieved April 12, 2019, from https://www.facebook.com/events/233856314126334/? notif $\mathrm{t}=$ plan user joined\&notif $\mathrm{id}=153401181732495$ 2

[26] Iyadurai, L., Blackwell, S.E., Meiser-Stedman, R., Watson, P.C., Bonsall, M.B., Geddes, J.R., Holmes, E.A. (2018). Preventing intrusive memories after trauma via a brief intervention involving Tetris computer game play in the emergency department: A proof-of-concept randomized controlled trial. Molecular Psychiatry, 23(3): 674-682. https://doi.org/10.1038/mp.2017.23

[27] Kandel, E.R. (2012). Biology and the future of psychoanalysis: A New intellectual framework for psychiatry revisited. The Psychoanalytic Review, 99(4): 607-644. https://doi.org/10.1521/prev.2012.99.4.607

[28] Bouvier, P., Sehaba, K., Lavoué, É. (2014). A tracebased approach to identifying users' engagement and qualifying their engaged-behaviours in interactive systems: application to a social game. User Model UserAdap Inter (2014), 24: 413-451. https://doi.org/10.1007/s1 1257-014-9150-2

[29] Asselborn, T.L.C., Faramond, V., Faucon, L.P. (2017). Unsupervised extraction of students navigation patterns on an EPFL MOOC.

[30] Coursera. (2019b). Data science. Retrieved May 19, 2019, from Coursera website: https://www.coursera.org/specializations/jhu-datascience

[31] Coursera. (2019c). Social Psychology. Retrieved May 19, 2019, from Coursera website: https:/www.coursera.org/learn/social-psychology

[32] Human Brain Project. (2018). Introduction to the HBP Curriculum: Interdisciplinary Brain Science. Retrieved from

mhttps://www.youtube.com/watch?v=meOT1sWGZ9g \&list=PLvAS8zldX4CgZgjFW14PE3BcPDjTUdsTz\&i ndex $=1$ 